\title{
EXPERIENCIA, ESCRITURA Y DELIBERACIÓN: EXPLORANDO CAMINOS DE LIBERTAD EN LA FORMACIÓN DIDÁCTICA DEL PROFESORADO*,1
}

\author{
José Contreras Domingo, \\ de la Universidad de Barcelona
}

\begin{abstract}
ResUmen: Este artículo presenta una reflexión que involucra la experiencia del autor como formador de profesores, lo que refuerza el hecho de que esta función es el trabajo más difícil del mundo, pero también uno con el cual él se siente más identificado y preocupado. El autor asume la necesidad de una transformación en la forma en la que hemos diseñado y trabajado con relación a la formación de los profesores, dando oportunidad a nuevas formas de ver la formación y los sujetos de esta formación. Cuando se habla de la posibilidad de transformar esa relación en los contextos de formación, él afirma que esta también pasa por el movimiento de transformación del mundo y de la escuela, lo que involucra caminos hacia la libertad.
\end{abstract}

Palabras claves: Escuela. Didáctica. Formación de profesores.

"Enseñar es como dar lo que no tengo" (Elizabeth Ellsworth)

"Nadie enseña en abstracto" (Vivian G. Paley)

\section{INTRODUCCIÓN}

La formación de profesorado es para mí el oficio más difícil del mundo, y a la vez el que más me atrapa, con el cual me siento más identificado y preocupado. Es el oficio más difícil para mí, y quizás, debería decir que lo ha sido, pero hoy ya no lo vivo tanto así, esto es, ya no lo vivo tan vinculado a la experiencia de la dificultad. Lo que no ha variado es el hecho de atraparme, si

\footnotetext{
* Artigo recebido em 12/06/2012 e aprovado em 15/09/2012.
} 
bien también se ha modificado la forma en que esto ocurre, así como algunas de las razones para ello. Durante mucho tiempo, la dificultad en mi tarea en la formación de docentes la he vivido como frustración, incapacidad y fracaso. Tenía la sensación de que los caminos que intentaba en mi trabajo con futuros enseñantes conducían a callejones sin salida. Me veía en atolladeros, entre algo que siempre he intuido sobre el sentido de enseñar Didáctica en la formación de maestros y maestras, y el no encontrar la manera en que eso que intuía fuera lo que constituía mis clases. Sin embargo, puedo decir que, en los últimos años, paulatinamente he ido vislumbrando algo mejor en $\mathrm{mi}$ camino para la formación de docentes. Eso no lo hace más fácil, pero ahora la dificultad para mí no significa frustración, incapacidad y fracaso. Ahora entiendo y sé encaminarme en este oficio, sabiendo que la dificultad significa improbabilidad y el azar, apertura a lo desconocido, no sé lo qué pasará, pero a la vez camino para explorar un sentido y una forma de adentrarse en ese sendero cada vez más desconocido. Creo que, con los años, entiendo algo mejor la naturaleza de la formación del profesorado y sé qué es lo que busco. Eso no lo hace más fácil para mí, ni siquiera me da más seguridad de hacerlo mejor, pero no es un sentido de frustración lo que llena ahora mi experiencia de dificultad, sino otra cosa que todavía no sé expresar bien y que tiene que ver con la conciliación entre la dificultad y yo, y por lo tanto, la capacidad de atravesar la incertidumbre constitutiva de la formación docente, una incertidumbre, que por otra parte, es igual a la de cualquier actividad educativa, para explorar los caminos en los que buscamos, no sólo yo, sino también mis estudiantes, el irse haciendo docentes. Unos caminos que a mi entender sólo hacen sentido educativo para la formación del profesorado si son caminos de libertad.

Explicar todo eso, esos cambios que se están produciendo en mi manera de ver la formación del profesorado, en mi forma de vivir ese oficio, en mis presupuestos, mis maneras de ver y de hacer en las aulas de Magisterio, es lo que me gustaría compartir hoy con ustedes aquí. Lo quiero hacer porque creo que así conseguiré resolver mejor una serie de asuntos que me parecen fundamentales en la formación del profesorado, asuntos que he podido descubrir, a veces con dificultad, sobre todo en esos últimos años de mi vida profesional como profesor de Didáctica.

La razón para hablar de mí experiencia, o mejor, desde mi experiencia, no es una cuestión de ego. Al contrario, creo que es eso lo que permite, al impedir la universalización de las ideas y al exponerlas apegadas a lo vivido con sus vericuetos y dificultades, ver mejor los matices, limitaciones y peligros (o a veces flagrantes contradicciones) de lo que trato de exponer. Como 
también permite entender mejor, la naturaleza de lo que quiero plantear: que no se trata de un método, si por eso se entiende una manera de fijar el hacer; tampoco de una abstracción, si por eso se entiende una buena idea, pero que no se sabe qué hacer con ella. Lo que trato de mostrar es lo que hay en juego, para mí, en la formación del profesorado, en su materialidad, en un hacer concreto, mostrando sus dificultades y problemas, pero sobre todo sus tensiones. Trato de mostrar que la dificultad no es el problema de la formación del profesorado, sino su naturaleza, que la dificultad puede significar apertura y posibilidad, en vez de frustración o negación, que esa apertura sólo puede nacer de mi conciliación con la dificultad, todo eso, creo, sólo puede ser expresado y entendido desde la experiencia. No se trata, por lo tanto, de lo bien que lo hago, sino de la tensión de lo que busco. Es hablando en primera persona, bregando por ese abrir posibilidades de camino, o sea, posibilidades de experiencia para mis clases con mis estudiantes, como pienso que cada uno de ustedes puede crear su propia relación personal para imaginarse haciendo lo mismo: explorando sus tensiones y buscando sus palabras para dar sentido a todo ello, viéndose en la situación y poniéndose en juego. Es al ponerse en juego cada uno, imaginándose en las circunstancias de mis clases, mis problemas y la forma en que hablo de ellas, o procuro buscarles sentido, como cada uno puede - $o$ al menos eso espero - analizar, significar y sacar conclusiones por sí mismo para su propia experiencia.

\section{EXPERIENCIA Y SABER}

Estoy tratando de expresar una posición respecto a la forma que, al menos yo, necesito para hablar de la formación del profesorado, y que para mí es la forma que necesitamos para hablar de la educación, sobre todo si nuestro interés no es el de atesorar conocimientos sobre un tema, sino el de estar implicados en una tarea que requiere de nosotros que nos pongamos en juego; $y$, ponernos en juego, lo hacemos nosotros: tú y yo, es decir, cada uno y cada una, desde su especial forma de ser y de entender, desde su disposición, subjetividad y singularidad. Esa tarea, además, no sólo depende de que nos pongamos en juego, sino de lo que ocurre en la relación, en el encuentro con otros y otras; algo no determinado, no determinable, a no ser que en esa relación se pierdan las cualidades del sentido educativo, o sea, la apertura a que algo pueda suceder y en donde cada uno pueda relacionarse desde sí, implicándose subjetivamente. ${ }^{2}$

La tarea educativa, como nos recuerda Van Manen, necesita entenderse y pensarse en su particularidad, preguntándose, en esa concreción, acerca de lo que allí ocurre, acerca del significado de lo que 
sucede, del sentido que tiene, dela huella que deja; es necesario preguntarse por lo adecuado a la situación: “era eso lo que había que hacer?"3 Por eso, necesitamos pensar en la tarea educativa en cuanto experiencia, ${ }^{4}$ o sea, como acontecimiento singular que es vivido y significado subjetivamente, que no se deja generalizar fácilmente, que impregna nuestro ser y que deja siempre abierta la pregunta por el sentido, por el significado, por el valor de aquello que es vivido. Pensarla en cuanto experiencia es, además, una apertura a lo que ocurre, un aceptar lo inesperado, un preguntarse por lo que realmente ha pasado y qué ha hecho en nosotros o en otros. Pensar la experiencia no es, por lo tanto, - como docentes - atender a la práctica, si por esto entendemos tan sólo el hacer que propiciamos, sino abrirse a la escucha de lo que realmente sucede y a la pregunta de lo que eso realmente significa, es decir, la forma en que lo que ocurre toma significado para nosotros.

Pero, pensar la tarea educativa en cuanto experiencia es algo más que dejarse informar por lo que pasa, es también disponerse, pre-disponerse a que lo que compone nuestro hacer docente pueda tener las cualidades de la experiencia. En otras palabras, es prepararse para que el espacio educativo sea un lugar en el que pueda suceder algo a ellos (mis estudiantes) y a mí. Porque esto es lo educativo: aquello que a uno le llega, le señala, le significa y le mueve a hacer algo con ello.

La pregunta es ¿qué es lo que nutre nuestra posibilidad y disponibilidad al encuentro educativo, y a que éste pueda ser vivido como una experiencia? ¿Cuál es el saber que nos ayuda en eso? Durante mucho tiempo, hemos pensado esta cuestión en términos de teoría y práctica. Como si se tratara de aclarar el conocimiento que explica o se aplica a la acción, o de conducir la práctica guiándose por proposiciones. Sin embargo, al formular la pregunta, he dicho expresamente "saber", y cuando digo saber no me estoy refiriendo a conocimiento, o a teoría. Digo saber precisamente por su apertura de significados porque se refiere a más dimensiones que las conscientes, las expresables, las verbales, o las cognitivas, y porque nos remite a la sabiduría, que es una especial disposición anímica (es decir, del alma) en la relación con el mundo. “El saber - dice María Zambrano - es experiencia ancestral o experiencia sedimentada en el curso de una vida"5. Sí, el saber es experiencia.

El saber no puede separarse de la experiencia; necesita mantenerse en relación viva con ella porque es a partir de esto, de la experiencia, de donde nace la inquietud pedagógica, la pregunta por el sentido y por lo adecuado. El saber qué sostiene el hacer educativo (mi hacer educativo, tu hacer educativo) nace de lo vivido y de lo pensado como propio (esto es, pensado como una experiencia), y necesita hacer el recorrido de sentido, 
disposiciones y vivencias que orientan el hacer: mi hacer $y$ tu hacer. El punto, pues, no es conocer cuál es el conjunto de explicaciones y proposiciones que anteceden a la acción (que es el modo en que se formula el problema de la teoría), sino cuál es la "relación pensante con el acontecer de las cosas". Así es como lo expresa Luigina Mortarí:

Lo vivido es el acontecer de las cosas que cada cual vive; la experiencia se encuentra allá donde lo vivido va acompañado de pensamiento. El saber que procede de la experiencia es, por lo tanto, el que se mantiene en una relación pensante con el acontecer de las cosas, el de quien no acepta un estar en el mundo según los criterios de significación dados sino que va en busca de su propia medida.

Creo que esta cita permite entender mejor que la relación experienciasaber no se corresponde con la concepción ni con los problemas que siempre acarreamos sobre la relación teoría-práctica (una relación en la que siempre hay que preguntarse si la práctica responde a la teoría, si la teoría se puede aplicar a la práctica, el sempiterno problema de por qué los prácticos no aplican las teorías o por qué las teorías no les sirven a los prácticos). La experiencia siempre está ligada al saber (al saber de la experiencia, aquel que se introduce en el desarrollo de las cosas para significarlo, o para problematizarlo, o para iluminarlo), de la misma manera que la sabiduría, como nos anunciaba María Zambrano, está vinculada al vivir. La pregunta que tenemos entre manos ahora mismo es, en realidad, ¿qué puede ayudarnos a que lo vivido se acompañe de pensamiento?, de aquel pensamiento que no se aparta de lo vivido, pero tampoco se reduce a repetirlo, ni a atribuirle los significados ya establecidos; un pensamiento que busca, para ese pensar, como para el propio vivir, su propia medida.?

Como puede verse, lo que estoy formulando es el problema de la educación, y en concreto, para el caso que nos ocupa, el problema de la formación del profesorado. Más en concreto aún, para mí, el sentido de la Didáctica, si es que esta disciplina y su enseñanza quieren desempeñar la tarea de ayudar a orientar la acción educativa, nuestra acción: mi acción, tu acción. ¿Cuál es, pues, el saber que necesita la experiencia, el saber que ayuda a que lo vivido pueda hacerse experiencia? O incluso, ¿cuáles son las experiencias formativas que facilitan construir la relación experiencia-saber? ¿Qué experiencias ayudan a que se sedimente un pozo auténtico y personal de saber? $\mathrm{O}$ ¿cómo relacionarse con lo vivido, y qué hacer con ello para que el saber de la experiencia pueda fructificar? ¿Cómo aprender de lo que nos pasa? Cuando me hago todas esas preguntas no estoy sólo pensando en qué puedo hacer para el aprendizaje y la formación de mis estudiantes, 
futuros maestros y maestras, sino que también son preguntas que me dirijo a mí: ¿Cómo puedo abrirme a la experiencia y aprender de ella? ¿Cómo mi experiencia y lo que aprendo de ella - el saber que resulta de lo que vivo, de lo que me sucede con mis estudiantes -, lo revierto a las clases, no sólo como un mayor bagaje para hacer mejor mis clases, sino como aquel saber qué enseñar, o sea, como un saber didáctico, como Didáctica? Puesto que Didáctica, al fin y al cabo, es el saber de la experiencia de enseñar, de educar.

Parte de los cambios de los que quiero hablarles respecto a mi docencia en la formación del profesorado tienen que ver con este cambio de perspectiva. Y como pueden imaginarse, el hecho de que ahora me lo formule así, con estas preguntas, refleja ya de por sí el propio cambio de perspectiva. Ahora me pregunto por lo que considero el núcleo de la formación del profesorado de una manera que supone encontrarse ya en el camino de la respuesta, un camino que he tardado muchos años en vislumbrar.

\section{LA DidÁCTICA, SEPARADA DE LA EXPERIENCIA}

Durante mucho tiempo me he visto atrapado en una manera de pensar la Didáctica y su enseñanza, en la que no sabía entender la naturaleza personal del saber pedagógico y el vínculo íntimo, mutuamente constituyente, entre experiencia y saber. Desde que empecé en ese oficio siempre tuve claro que un maestro no realiza su tarea con los apuntes de Didáctica bajo el brazo; ni siquiera "sabiéndose" los temas de la Didáctica; que, lo que sea que él tenga como saber pedagógico, es lo que lleva puesto, incorporado, en su sentido literal, esto es, metido en el cuerpo, hecho cuerpo. Sin embargo, mi preocupación fundamental era hacerles entender a mis estudiantes los grandes argumentos de la Didáctica, con la esperanza de que su poder de convicción los condujera a realizar las grandes prácticas que yo deseaba para ellos. Está claro que yo estaba convencido de que había una dimensión emocional en todo esto, ideológica, utópica etc, que debería arrastrarlos a estas prácticas comprometidas. Pero, esto era para mí algo que tenía que nacer de la fuerza cognitiva, teórica, de las grandes ideas educativas, de la capacidad de la Didáctica para criticar las prácticas docentes y para proponer otras mejores. Yo estaba a la espera de leer en ellos, en sus reacciones, en sus trabajos etc, la forma en que entraban en ese "enardecimiento" que yo deseaba.

Conforme mi socialización académica fue aumentando, esa convicción se agravó, de tal manera que, en la medida en que iba configurándome el corpus básico de la disciplina, aumentaba mi tendencia a pretender que mis alumnos aprendieran el saber correcto, la Didáctica 
como un saber ya fijado: corrientes didácticas, categorías analíticas, teorías interpretativas de los procesos de enseñanza-aprendizaje, propuestas críticas para la enseñanza etc. Lo cual me hacía estar más pendiente de cómo se apropiaban de las conclusiones del conocimiento ya elaborado que de cómo se desarrollaba su capacidad de saber por sí mismos. Confundir la Didáctica con un conocimiento me hacía creer que poseer un buen discurso haría de mis estudiantes buenos maestros. De manera que, si bien podía ser evidente la desazón que mostraban ante la desconexión entre los contenidos de las clases y sus inquietudes no resueltas como futuros maestros, yo, sin embargo, no sabía entenderla, ni hacer nada con ella que no fuera un intento de refinar los discursos, elegir nuevos textos, plantearles nuevas tareas. De esa forma, paradójicamente, yo podía estar defendiendo grandes ideas para la docencia y, a la vez, sentirme perdido en mis propias clases; estaba intentando conseguir buenas argumentaciones, fundamentaciones, sistemas teóricos y sin entender qué pasaba con muchos de mis alumnos que veían eso como algo desconectado de sí. Pensaba que el problema estaba en mis estudiantes y en el fondo me mostraban (pero yo no lo podía ver) la auténtica naturaleza del problema: que el conocimiento didáctico que yo pretendía acercarles estaba desconectado de ellos, que no podían establecer conexiones; no había "puentes cognitivos", una idea que hace suponer que el problema no está en la naturaleza del conocimiento, sino en cómo lo "transportamos" a nuestros estudiantes. Ellos no podían establecer conexiones, de la misma manera que yo, que me sabía esos contenidos, tampoco lo podía hacer; tan sólo establecía conexiones mentales, o excitaciones ideológicas, pero toda esa Didáctica no era, o yo no sabía tornarla, como diría María Zambrano, una "forma actuante de conocimiento", ya no sólo en mis estudiantes, ni tampoco en mí.

Efectivamente, fue con algunos escritos de esta filósofa y también con la oportunidad de algunas experiencias profesionales y personales más ${ }^{8}$, y por supuesto, con mi insatisfacción por lo que me estaba pasando, con la intuición, que poco a poco germinaba, de que había una profunda desconexión entre mi vivir profesional y mi saber pedagógico (y que me revelaba un problema ya no en mi traslación a la práctica del conocimiento didáctico, sino en la forma de ser concebido ese conocimiento ${ }^{9}$ ).Con todos esos ingredientes, empecé a plantearme esas desconexiones, y empezaron también a aparecer ciertas reorientaciones que no fueron sólo profesionales, sino más amplias, ya que tenían que ver, en general, con la manera de relacionarme con mi propia experiencia, así como con la necesidad de repensar un saber que me excitaba intelectualmente, pero que no me ayudaba a orientar mi hacer. 
Escribe María Zambrano que vivimos una época en la que estamos llenos de ciencia y de técnicas, pero "pobre, inmensamente pobre, de todas las formas activas, actuantes del conocimiento"10 ${ }^{\prime 1}$. Con ello se está refiriendo a aquellas formas de conocer que son necesarias para vivir, o mejor, para emprender la vida con una intuición, con una visión, con una guía, y que ella relaciona con el saber de la experiencia, un saber que orienta la experiencia, el vivir, porque no se despega de ella. Hay un tipo de saber y una necesidad de saber, dice Zambrano, que no es ciencia, que no quiere "ascender a ciencia", que se resiste "a ascender al cielo de la objetividad"11, porque la vida necesita de la verdad, pero de su verdad. Hay un saber apegado al vivir, a la experiencia, y que tiene que ser así porque tiene que conectarse con la vivencia propia de quien lo comunica, y tiene que tener la posibilidad de conectarse también con la vivencia propia de quien lo escucha. Es un saber que no queda bien expresado como un simple conjunto de proposiciones, que es persuasivo, pero que no lo dice todo, ni puede hacerlo; porque hay cosas que no pueden decirse, que sólo pueden insinuarse, y a veces, callarse,"para que el otro - dice nuestra autora - sienta nacer dentro de sí lo que necesita y sea más suyo; para que lo sepa por experiencia también", para que el que escucha encuentre "dentro de sí, en status nascens, la verdad que necesita"12. Continúa así13:

La vida no puede ser vivida sin una idea. Mas esta idea no puede tampoco ser una idea abstracta. Ha de ser una idea informadora, de la que se derive una inspiración continua en cada acto, en cada instante; la idea ha de ser una inspiración... Hay verdades, las de la ciencia, que no ponen en marcha la vida. Las verdades de la vida son las que, introduciéndose en ella, la hacen moverse, ordenadamente; las que la encienden y sacan de sí, haciéndola trascender y poniéndola en tensión.

Esas reflexiones de María Zambrano me indicaban con claridad cuál era el problema: lo importante no era mi capacidad de transmisión de la disciplina de Didáctica, si ésta se había convertido en conocimiento separado de la experiencia. En otro lugar, esa misma autora, hablando de la filosofía, aunque creo que no nos cuesta nada extrapolarlo al conocimiento académico en general, y a la Didáctica en particular - comenta lo siguiente ${ }^{14}$ :

Ha sido una especie de imperativo de la filosofía, desde su origen mismo, el presentarse sola, prescindiendo de todo cuanto en verdad ha necesitado para ser... Así es como la experiencia de la vida queda separada del pensamiento.

He aquí el problema: haber hecho de la didáctica una disciplina que trata sobre las cuestiones de la enseñanza, pero haciéndola prescindir de lo que la ha hecho ser, o de lo que le da el mayor sentido de ser: su vinculación 
con las formas concretas de proceder y de pensar de quienes se encuentran en la vivencia pedagógica; o sea, desvinculándola de la relación pensante con el acontecer de las cosas. El auténtico conocimiento pedagógico, en realidad, sólo puede ser una forma actuante de pensamiento: un saber que insinúa, que ofrece la experiencia en su apertura a ser pensada y actúa como inspiración, sin sustituir el movimiento que tiene que hacer cada cual para conectarlo con su propia vivencia, para que inspire su propio pensar y hacer. Un saber que, a veces, lo que debe hacer es callar, crear el vacío en el que el otro pueda hacer emerger su propia verdad, una verdad que está tan sólo naciendo; que sólo podrá ser si llega a ser una experiencia propia.

\section{BÚSQUEDAS Y TANTEOS}

La lectura de Zambrano les dio más claridad y más consciencia a mis búsquedas y preocupaciones. Hacía ya algún tiempo que reformulaba distintos aspectos de mi docencia; por ejemplo, ¿quién era yo como maestro para mis estudiantes? ¿cuál era mi presencia ante ellos? ¿qué aprendían de mí como maestro y no como transmisor de un conocimiento? ¿cómo hacer del espacio de clase un lugar compartido, en el que pudieran sentirse reconocidos? Mientras buscaba formas de fijarme y atender a estos aspectos, también desterraba de mi enseñanza las formalizaciones más encorsetadas de la Didáctica, buscando textos y modos de enseñar que fueran más experienciales. ${ }^{15}$

En los años en los que me movícon esas aspiraciones y preocupaciones, al tiempo que veía con más claridad algunos aspectos, y me conectaba más en mi interior con una visión del saber pedagógico menos academicista, pude entender más tarde que, en mi enseñanza, seguía apegado a formas que se ocupaban de transmitir conocimientos; eso es, el saber de la experiencia, sin embargo continuaba insistiendo más en las conclusiones del saber que en la oportunidad de vivir la experiencia de saber, la posibilidad de elaborar un saber a partir de la experiencia, de hacer experiencia con lo vivido, pensando sin atenerse a lo dado. Resultaba, así, que transmitía con mucha pasión ese pensamiento de la importancia de la experiencia y del saber de la experiencia, pero con una forma de llevarlo a cabo que más bien funcionaba como una idea para que aprendieran y no como una vivencia para que la experimentaran.

Por otra parte, aunque pretendía que el tiempo compartido de clase, tuviera ciertas cualidades, pesaba en las relaciones el hecho de vivir las clases como un ambiente predeterminado por la trayectoria que marcaba, dirigido por una visión de la educación que, muchas veces, les resultaba a los alumnos desestabilizante en relación a sus experiencias y convicciones, 
pero que se movía desde mi conducción de las clases hacia una dirección a la que sólo podían entregarse o resistirse. El abismo que ellos no sabían resolver (y tampoco yo) era el que se abría entre lo que era, por un lado su experiencia escolar y lo que sospechaban que sería su trabajo en las aulas; y por otro, las críticas y contrapropuestas pedagógicas que yo les hacía; un abismo que algunos aceptaban como reto, pero que a muchos no sólo les creaba inseguridad, sino también un cierre mental. Por otra parte, en ningún momento podían apropiarse de su propio proceso de formación, llevar sus propias riendas, porque desconocían adónde íbamos, tan sólo podían confiar en mí, pero, en la medida en que no se sintieran seguros con el planteamiento didáctico que yo les estaba proponiendo para su labor como docentes, lo que se producía era pérdida, desconfianza, o rechazo, normalmente, pasivo. La cuestión no era que ellos tuvieran que aceptar planteamientos que no entendían o que no compartían, ya que yo les animaba a que defendieran sus propias visiones pedagógicas, sino que se sintieran desasistidos, porque no tenían forma de mediación.

Mis clases estaban centradas en un plan de enseñanza en el que se recorrían los temas a partir de unos textos y de unas actividades con los mismos para entender lo que proponían esos autores, con la ilusión de que sería eso lo que movería su sentido de la experiencia como algo por construir. Entendiendo de una manera equivocada a Zambrano, pensaba que habría algo en lo que yo les enseñaba que funcionaría como"verdades que pondrían en marcha la vida". Pero, como ella misma me señalaba en ese mismo texto y yo todavía no lo había captado, "la experiencia se transmite únicamente al ser revivida, no aprendida". ${ }^{16}$ La verdad que cada uno pueda aprender, la que pueda tomar de la experiencia - del saber de la experiencia - como inicio y nacimiento de la propia verdad, aquella que cada uno necesita, sólo cobra su sentido al ser vivida, transformando así la propia vida, pero no de una manera abstracta (como eso que he llamado "enardecimiento"), sino como disposición a la experiencia concreta.

Poco a poco estaba aprendiendo conmigo (fijándome en mí, mirándome en mi interior como docente, en las vicisitudes concretas y en lo que me pasaba y sentía) que el saber pedagógico, las posiciones pedagógicas no son sólo ideológicas, o "enardecimientos" pasionales, sino que son íntimamente personales, en las que una sensibilidad y una apertura se fraguan, encontrándose siempre con los límites y con las dificultades que no son sólo convicciones o deseos abstractos, sino que tienen que pasar por el propio cuerpo. El aspecto de la experiencia y de la relación experiencia-sabiduría toca en otros puntos, remueve otras cosas además de la comprensión racional, 
y no se trata de una simple añadidura del "componente emocional". Aquí entran en juego tanto el deseo como el miedo, tanto las ilusiones como la inseguridad, tanto una indefinida idea, o vagas visualizaciones de nuestras aspiraciones, como la necesidad de formas concretas para vivirlas y realizarlas. Nuestra manera de mirarnos, de mirar al mundo y de dar significado a lo que hay y a lo que queremos o podemos está atravesada por todo eso, abriendo o cerrando nuestra capacidad interpretativa, nuestro conocimiento y nuestra relación con el hacer. "La experiencia se transmite únicamente al ser revivida, no aprendida."

¿Qué debía aprender yo de esta verdad? ¿A qué me llamaba esa visión clara en relación a mis clases, a la formación de mis estudiantes como docentes?

Es evidente que no estamos hablando aquí de experiencia en el sentido de practicar una actividad. De lo que se trata es del saber de la experiencia, porque como dice Zambrano, la experiencia es el conocimiento que no se desconecta del vivir en concreto, en su suceder temporal. "Todo vivir es en el tiempo, y la experiencia no es sino el conocimiento que no ha querido ser objetivamente universal por no dejar al tiempo solo"17. Además, en mi universidad, el momento de las asignaturas llamadas "teóricas" (a las que yo me dedico) está separado del momento de lo que llaman el "prácticum" - el tiempo que los estudiantes pasan en las escuelas de educación primaria. ¿Cuál era entonces la experiencia que yo les podía proporcionar para su formación interior como maestros? ¿Cómo labrar la relación entre experiencia y saber? Experiencia no en el sentido de "haber practicado", sino en el de haber puesto los cimientos para que algo pueda suceder y para pensar lo vivido sin repetir lo dado, buscando una medida. ¿Cómo adentrarse a la posibilidad de la experiencia como sentido de la Didáctica y de la formación del profesorado? ¿Cómo compartir con mis estudiantes el proceso de relación entre experiencia y saber? Un saber pedagógico que pueda surgir de la experiencia vivida, y que permanezca conectado a ella, orientando su sentido, preguntándose por su sentido. Una experiencia que se pueda sintetizar como saber, como el pozo de sabiduría que deja el vivir pensado. Un saber que nos ponga en disposición de vivir una experiencia. ${ }^{18}$

\section{NuEVOS CAMINOS}

Con avances y retrocesos, he vislumbrado, en los últimos años, un camino que, aunque para mí se concreta en la Didáctica, creo que está más allá de programas y determinaciones disciplinares. Es un camino de búsqueda en el cual vivir y explorar esas preocupaciones que antes enunciaba. Pero, 
un camino de búsqueda no se refiere a una carretera delineada, que por sí sola conduce al destino que ya está anticipado en su trazado. Al contrario, mi propia experiencia en ese camino me muestra que no me puedo fiar de que él solo me conduzca bien, si yo no estoy allí, preguntándome continuamente por lo que me orienta, cuál es la búsqueda, qué es lo que me guía y si era por ahí por donde debía ir.

¿Qué es lo que me guía?

Creo que podría decir que lo que me guía es que lo que componga el curso, lo que hagamos, lo que tratemos y lo que busquemos no esté desconectado de nosotros: de quienes somos, de cómo vivimos, de lo que nos pasa, de lo que queremos. Lo que me guía es explorar con mis estudiantes lo vivido, lo que saben (lo que sabemos), lo que hacen (lo que hacemos), lo que quieren (lo que queremos), tanto en nuestras clases como en sus propias vidas, en sus historias, en sus experiencias. Que no estén desconectados de nosotros no es algo que se reduzca a una cuestión de identidad; no se trata de una afirmación del Yo. Se trata, como plantean las autoras del feminismo de la diferencia, de partir de sí, pero para ir en búsqueda de lo otro. Partir de sí supone "partir de", pensar la experiencia de nuestra singularidad (entretejida de relaciones que nos hacen ser quienes somos), pero también "partir hacia", por lo tanto, alejarse de la experiencia, para, yendo más allá, abrir nuevas comprensiones y posibilidades, tanto de sí como de las relaciones y de las posibilidades con lo otro y con los otros. Tal cual lo ha explicado Anna $\mathrm{M}^{\mathrm{a}}$ Piussi $^{19}$, partir de sí significa:

hablar del mundo y al mundo situándose en el punto en el que se está, el punto de nuestra subjetividad entretejida de vínculos reconocidos (o silenciosos pero significativos), para opinar, pensar y actuar: exponerse en el espacio abierto de las relaciones plurales, en el juego arriesgado de la realidad, para hacerla (y hacerse) ser según un nuevo inicio.

Lo que me guía, pues, es que las clases puedan ser un ambiente de experiencia en el cual partir de sí, y un ambiente en el que se pueda experimentar e imaginar el actuar desde sí. Partir de sí y actuar desde sí, como he podido intuir con Luisa Muraro ${ }^{20}$, son experiencias de libertad en vez de afirmación del Yo, cuando son vividas como exploraciones de apertura a lo desconocido de sí, de apertura a la posibilidad de lo otro, la posibilidad de los otros, de las otras, junto a mí, en relación a mí. Me guía, pues, que mis estudiantes en nuestras clases puedan pensar lo vivido, su mirar, su hacer, desde sí, pero abriéndose a lo otro, a los otros. 
De la forma como ahora lo veo y soy capaz de explicarlo, diría que tengo tres ámbitos de preocupación para andar en mi camino de búsqueda: en primer lugar, el espacio en sí de las clases y el qué hacer para que éstas se abran a la posibilidad de ser vividas como experiencia; en segundo lugar, el contar con las propias vivencias y experiencias de mis estudiantes, con lo que ya tienen y les puede dar la pista de lo que puede ser el camino a recorrer, a clarificar y a ahondar como maestros o maestras; y, en tercer lugar, cómo traer a la clase experiencias, o sea, formas de hacer de los docentes que tengan la cualidad de lo que puede ser vivido como experiencia; y la tarea es conseguir que eso no sea una anécdota, sino que pueda vivirse como algo que se pone en relación con uno mismo, que le interroga, que le hace ver caminos y posibilidades, que le empuja a pronunciarse.

En todos esos espacios, la cuestión para mí es ¿qué hacer para que la cualidad de la experiencia pueda fraguar?; ¿qué hacer para cuidar la posibilidad de que algo nos pase, y para que ese algo nos empuje a la necesidad de pensar, para verse cada uno y cada una en la necesidad de pensarse en relación a lo otro, de abrir posibilidades al sentido de lo educativo, al deseo de las relaciones educativas fructíferas y sensatas, teniendo en cuenta quienes somos, con quienes estamos, a quienes cuidamos?

Quisiera hablarles sobre tres aspectos que, en esos momentos, me ayudan a dar forma a todas esas preocupaciones. Son formas de pensar, en mi práctica docente, en las cosas que les propongo a mis estudiantes y que a mí me orientan en el sentido de concretizar mi búsqueda. La primera es la escritura de la experiencia; o mejor, la escritura como el proceso por el cual la vivencia puede pasar a la experiencia. La segunda es lo que llamo aprendizaje personal, un propósito que me conduce en todo el curso y que trato de que mis estudiantes vivan como propósito para ellos y como traducción propia de todo lo que hacemos. En realidad, esas dos ideas no son cosas separadas, no son dos prácticas diferentes; son más bien dos formas de encontrar la expresión de lo esencial en la construcción de la experiencia-saber. Por último, todo lo que tiene que ver con el hacer cotidiano en el aula: la clase como el espacio en donde fraguar relaciones de confianza y en donde experimentar esta búsqueda de sentido, esa pregunta por lo educativo y en donde sostener esta aspiración al aprendizaje personal y a la escritura reflexiva es fundamental para que algo de eso se pueda vivir.

\section{ESCRITURA PERSONAL-REFLEXIVA X ESCRITURA PROFESIONAL}

Considero que escribir desde sí, explorarse, entenderse en lo que a uno le pasa en las situaciones educativas, está en el núcleo de la tarea 
docente. La enseñanza es un oficio muy delicado, no sólo porque tratamos con otras personas, sino también porque tratamos con nosotros mismos. Lo que siempre está en juego, en cuanto docentes, en cualquier situación educativa, es ¿qué significa para nosotros?, ¿qué se nos presenta para hacer?, ¿qué pensamos que tenemos que hacer?, ¿cómo nos relacionamos con eso que nos pasa, o se nos presenta, o pensamos que tenemos que hacer?, ¿qué estamos en condiciones de hacer? y ¿qué es lo que realmente hacemos? Sin embargo, es demasiado habitual encontrarse con una tendencia a dirigir la mirada hacia afuera, hacia el plan de enseñanza, hacia los alumnos, hacia lo que le pasa a uno, o a otro. Hay toda una didáctica construida con esa mirada hacia afuera.

Cuando hablo de escritura personal, reflexiva, me refiero a la forma de volver esa mirada hacia nosotros, de hacer una didáctica que no abandone la indagación de sí. Una indagación que no es simple subjetividad, sino que es una búsqueda y comprensión del sentido con el que se viven las cosas, de la forma como nuestro pensamiento está moldeado por lo vivido, o de la forma como, deteniéndonos a pensar, a escribir, a ordenar el relato de lo vivido y de lo que eso significa para nosotros, no dejamos que las cosas simplemente pasen, sin habernos preguntado ¿qué significa eso para mí? ¿qué produce eso en mí? ¿qué hago ahora con esto que he vivido?

Tengo la convicción de que la escritura profesional que necesitamos los docentes no tiene mucha relación con los registros de la escritura académica. Nuestra escritura profesional, como docentes, está más relacionada con la escritura narrativa ${ }^{21} \mathrm{o}$, en todo caso, con la escritura personal-reflexiva, en la que intentamos poner lo vivido en relación con lo que nos hace pensar, lo sentido con el intento de captarlo, lo pasado con lo que nos sentimos llamados a hacer.

Entiendo que la narrativa tiene una especial importancia en esa forma de escritura personal-reflexiva, porque es la que nos permite situarnos en la dimensión temporal propia de la experiencia y hablar desde ella siendo parte del relato ${ }^{22}$, explorando la relación entre lo que se cuenta y el significado que se le atribuye; de esa manera, la narración permite expresar la experiencia de saber, y no un saber sin la experiencia que lo ha hecho posible. ${ }^{23}$ Igualmente, creo que hay otras formas de escritura (creativa, con componentes artísticos, o hasta ficticia), así como otras formas de expresión que son valiosas porque mueven la sensibilidad perceptiva, la imaginación; mueven la mente y la emoción hacia terrenos que no siempre son fáciles de explorar bajo formas de expresión tan racionalistas como suelen ser las formas de escritura académica. ${ }^{24}$ 
En cualquier caso, sea en forma de relato o no, contando experiencias y peripecias o tratando de aclarar las direcciones que uno quiere o no recorrer como docente, en función de lo vivido y experimentado, mi búsqueda ha sido la de abrir en mis clases oportunidades para probar esa escritura personal sobre lo vivido. Que esa escritura sea la ocasión de aclarar el sentido de la experiencia, de captar en lo vivido lo esencial del encuentro educativo y de buscar, en todo ello, lo que les pueda servir de inspiración a los alumnos en su hacer pedagógico.

Tengo una preocupación que no siempre sé comunicar bien a mis alumnos, que puedan rastrear aspectos que normalmente se viven de manera implícita y con un sentido muy íntimo, que puedan fijarse, sobre todo, en su experiencia del amor, de la atención, de la calidad del encuentro respetuoso, del cuidado; sea en su ausencia y en su necesidad. Porque justamente las dimensiones más importantes que necesitan para su labor educativa no se pueden enseñar; pero lo que no podemos hacer es abandonarlas a un terreno del que no se habla, sobre el que no intentamos aclarar, depurar su sentido. ${ }^{25}$

Escribir sobre la historia de su infancia ${ }^{26}$, por ejemplo, es ponerlos a prestar atención en sí mismos, para buscar en sí aquello que tienen que lograr descubrir y aclarar para establecer su relación con los niños y las niñas. Si se revisa la experiencia vivida, es más fácil sondear lo que no se puede enseñar, pero se puede preguntar y buscar dentro de sí mismo porque, fijándonos en nuestra niñez, si nos sabemos mirar bien (esa es la tarea difícil y que no siempre, ni con todos, consigo hacer), podremos saber qué fue bueno o malo en nuestro crecimiento. Relatando experiencias que viven en la actualidad, como educadores, es posible que se detengan a pensar en aspectos personales y en sus capacidades y dificultades de apertura delante de la necesidad del otro, en lo que les parece sensato y adecuado, en cómo se sienten, en qué desean etc. ${ }^{27}$

Una de las formas más interesantes que he descubierto con relación a ese probar y vivir una escritura reflexiva ha sido la del diario de clase. Una forma que probablemente se ha mostrado fructífera porque es la menos determinada. Se basa en un simple compromiso de escribir cada día un texto para la clase, con total libertad. Eso hace con que el registro de diarios sea muy variado. Pero, todos tienen en común lo que caracteriza un diario: cuando uno escribe, se muestra, o muestra su relación con lo que relata. Los diarios nos permiten compartir las distintas formas que cada uno tiene de vivir lo que pasa en la clase, el sentido de la asignatura en general, el sentido de ser docente o lo que les inquieta en su futuro profesional. Pero, a veces, es la oportunidad que se tiene para contarle al grupo cosas que se quieren 
compartir, ya sean personales o no. Ese medio expone quiénes son y cómo se sienten, sus preocupaciones o convicciones, sus agrados y desagrados respecto a la clase, la asignatura, el profesor, o lo que ocurre en clase, y no sólo aquello de lo que trata, a veces también lo que piensan del mundo y de la vida, de su vida en la Universidad (en la que la mayoría se está iniciando) o de lo que para ellos significa ser jóvenes y estar poco a poco adentrándose a un oficio y viendo que se les acerca el momento, que no podrán postergar, de hacerse cargo de sí mismos, de asumir su propia vida etc.

Aunque, como se pueden imaginar, mis preocupaciones cuando empecé a poner en marcha esta tarea eran que se favoreciera la reflexividad sobre el contenido de la clase $y$, a la vez, que se analizara lo que hacemos, porque, aunque no están en prácticas, toda clase en la que participan es una práctica, especialmente en Didáctica, ya que la clase trata de lo que hacemos ${ }^{28}$. A pesar de tener interés en el diario como un ejercicio, probablemente el más típico de la creación de la experiencia al reflexionar sobre lo vivido, lo cierto es que he podido descubrir que el diario de clase es más, mucho más, que eso. Al extremo de poder decir que es lo más importante que hacemos en el curso, puesto que se hace todo lo demás en clase, sin lo cual el diario no tendría esa naturaleza. Entiendo que el diario significa vivir principalmente lo que es más importante en toda relación educativa: el poder ser - ser reconocido; decir quien se es; presentarse; proponer, exponer lo que se tiene, lo que se sabe, lo que se piensa; $y$ compartir lo que ya se tiene, el propio bagaje, las propias preguntas, las curiosidades y preocupaciones; poder ser alguien que tiene la capacidad de establecer sobre que hablar, lo que se tiene a decir etc. Eso es importante y lo primero en cualquier experiencia educativa que no sea instrumental, sino que aspire a ser experiencia de vida. Por lo tanto, el punto no es si se trata de educación, sino si se trata de ellos o de nosotros: de ellos y ellas y de mí, del hecho de que seamos un grupo y lo estemos construyendo al poder compartir. ${ }^{29}$

El diario se ha convertido, para mí y para la clase, no sólo en lo que nos ayuda a construir la experiencia, sino en una experiencia en sí misma. Es un momento en el que vivimos algo que tiene una intensidad especial, que nos hace vivir con todos los sentidos En muchas ocasiones, los comentarios que se suscitan, nos han conducido a compartir clases con una magia especial o nos han obligado a aclarar cosas fundamentales para que la clase pueda cobrar un significado importante en relación al hacernos maestros. De esa manera, lo que el diario nos despierta como tema de reflexión, o como espacio para compartir aquella historia que alguien nos ha querido contar, acaba siendo la oportunidad para pensar en lo que sabemos y lo que no sabemos, en lo 
que hacemos y lo que no hacemos, en las razones para nuestro hacer (que en muchos momentos es mi oportunidad de explicarles por qué les planteo o hacemos lo que hacemos). Es el mejor momento para que el hacer de la clase y el pensarla confluyan; y para que lo que nos pasa, o lo que pensamos, se vuelva un motivo de reflexión pedagógica. Además, nos ha mostrado una forma de hacer la enseñanza y de vivir una relación educativa que se convierte en una vivencia importante respecto a qué hacer y qué cuidar en la relación con los alumnos, una vivencia que ellos incorporan, ya no sólo en la materialidad del diario, sino en las cualidades educativas que nos permiten vivir y percibir. Muchas de las cuestiones que a mí me preocupan en la educación escolar de la infancia y que quería hacerles entender han encontrado su expresión en la experiencia del diario: escuchar a los niños, atenderles en su mundo, en lo que son y quieren compartir, poder ser quienes son y poderlo expresar, sin ser juzgados, iniciar auténticas conversaciones, cultivar la sensibilidad para ver detrás de las apariencias, captar la singularidad de cada uno y de cada una etc. Por todo eso, el diario ha resultado ser una experiencia de la relación entre experiencia y saber.

\section{Aprendizaje personal X Aprendizaje deliberativo}

Como ya indicaba anteriormente, en realidad, eso que desencadena la escritura personal, para mí, no es sólo una cuestión de experimentar ciertas vivencias con mis estudiantes. Entiendo que aprender (la Didáctica o cualquier otra cosa) debe ser poder hacer algo propio con lo que nos llega como novedad. ${ }^{30} \mathrm{El}$ verdadero aprendizaje siempre es algo personal. En mi caso, trato de que las clases puedan ser un lugar en el que se puedan acoger experiencias, pensamientos, discursos, relatos sobre la enseñanza y el aprendizaje; sobre las relaciones con los niños; sobre lo que se puede mirar y ver en la infancia, y en nosotros al compartir nuestro tiempo con ella; sobre lo que vale la pena que los niños experimenten y aprendan y lo que eso significa para nosotros como docentes, lo que es o no posible en los espacios escolares y a dónde nos lleva esa reflexión etc. Entiendo que mi tarea consiste en poner a los estudiantes en el camino en que eso pueda ser escuchado, visto, probado y pensado; pero, cada uno y cada una tiene que hacer después sus propias cuentas con todo aquello; tienen que hacer su propio proceso y llegar a sus propias conclusiones. ${ }^{31}$

Ha sido eso, entre otras cosas, lo que me ha conducido a centrar cada vez más el trabajo del curso en actividades y tareas con las que los estudiantes tienen que lidiar, que no son transmisiones en las que yo controlo del contenido del saber. ${ }^{32}$ De esa forma, tener que resolver tareas complejas 
les hace estar pendientes de la relación entre ellos, la propuesta de la tarea y la documentación que necesitan, asumiendo las direcciones que quieren tomar. Las clases son para mí el lugar del sentido, el lugar en el que intentamos ahondar en el sentido de esas tareas para su formación como docentes. Lo que espero de ellos y de ellas es que puedan poner la asignatura y sus tareas al servicio del hacerse maestros y maestras. ${ }^{33} \mathrm{~A}$ sabiendas de que las propias formas institucionales de la enseñanza crean una división en ese propósito, porque, si bien mi aspiración es que los alumnos puedan vivir como docentes en formación y que puedan vivir la asignatura desde ese interés, lo cierto es que todo en la universidad les dice otra cosa. Les dice que se trata de vivir como alumnos; o sea, de atender a las presiones de las calificaciones, del expediente académico, del aprender como acumulación del conocimiento correcto, del saberlo con corrección académica (eso es, el juego teoría-práctica), del saber qué quiere cada profesor y del cómo salirse ileso de todo eso. No quiero que salgan ilesos, sino tocados. ¿Cómo conjugar todo eso? ¿Cómo pueden arriesgarse conmigo?

Esa es una de las razones por las que pienso que el aprendizaje personal es, al menos en el contexto institucionalizado del que disponemos, un aprendizaje deliberativo. Por supuesto, lo ha de ser, ya que lidiamos con asuntos de naturaleza deliberativa. La cuestión de la educación es siempre deliberativa, situacional, y, por eso, personal, es decir, es una cuestión de que quien asuma la responsabilidad educativa en el encuentro tendrá siempre que responderse a sí mismo. Además, la propuesta de llevar a cabo un aprendizaje que asume su naturaleza personal implica enfrentarse a la deliberación, porque lo que tengo que hacer no me llega resuelto; lo que tengo que plantearme es en qué dirección debo llevar lo que me llega como nuevo y qué hacer con ello, eso no está decidido. Además, en el marco institucional, tengo que resolver la relación conflictiva entre el sentido personal del aprender y las soluciones institucionalizadas que le doy: ¿qué relación hay entre aprender $y$ atender a las demandas del profesor; entre hacer algo personal y desarrollarme con éxito en las exigencias institucionales; entre seguir la inercia que me hace un alumno y pensar quién soy yo, cuando asumo mi proceso de aprender y tomo las riendas de mi hacerme maestro? Entiendo que todas esas preguntas y procesos deliberativos suponen un inicio para enfrentarse al conflicto deliberativo del oficio docente, atrapado entre las exigencias institucionales y las demandas pedagógicas.

Con relación a ese propósito, mi aspiración es que todo esté continuamente en enfrentamiento, las presiones, inercias y demandas institucionales, por un lado y lo que iniciamos y les propongo y que 
obedece a otras motivaciones, que no las de jugar los roles de profesor y alumno ${ }^{34}$. Mi aspiración es que podamos ser profesor y estudiantes, pero no en representación de las expectativas de la institución, sino con voz propia, siendo quienes somos, yo, por mi parte, con la responsabilidad de encaminarlos a las preguntas que esconden el querer ser docente, y los estudiantes, por su parte, asumiendo la responsabilidad de hacerse maestras y maestros y ir encontrando la forma de hacerlo. Como pueden imaginar, eso sale a relucir, muy a menudo, en muchos de los debates que se originan en el diario, en las preocupaciones que los estudiantes manifiestan por la evaluación y la calificación, y en las conversaciones más particulares que mantengo en tutorías. Además, procuro que las tareas que les propongo se muevan siempre en el plano de que enfrenten sus propias visiones y posiciones y relacionen lo educativo con los marcos institucionales, para que piensen qué hacer. ${ }^{35}$

\section{EL AULA, UN LUGAR DE RELACIONES}

Precisamente por todo lo que he dicho anteriormente, el espacio del aula, el encuentro cotidiano en clase, es un momento fundamental en todo el proceso que busco. Ya decía antes que la enseñanza es un oficio delicado, porque tratamos con nosotros mismos. Aún más en clases en las que tratar consigo mismo es algo que deseo que ocurra, que sea una posibilidad para quien quiera aprovecharla, un lugar en el que hay que hacerlo posible, pero nunca imponerlo, ni siquiera esperarlo. La oportunidad de que algo suceda, de que algo nos toque, nos involucre personalmente, nos conduzca a la necesidad de preguntarnos íntimamente por nosotros mismos y por nuestra relación con los otros y con lo otro; la posibilidad de ponerse en juego personalmente, hablar de sí y desde sí, incluso "exponerse", todo eso sólo puede ocurrir si se cuidan las relaciones de confianza. Por eso, para mí, el espacio de la vida cotidiana en el aula es tan importante, es el auténtico lugar educativo, el de la relación y de las múltiples relaciones.

No son sólo las relaciones personales, sino las relaciones de sentido, en el seno de las relaciones personales. Mi búsqueda cotidiana es la del cómo hacer para que podamos vivir el encuentro del aula como un lugar donde establecemos relaciones: entre lo que decimos y lo que hacemos, entre lo que piensan unos y lo que piensan otros, entre lo que me llega y lo que pienso y siento; entre lo que llego a entender y saber y lo que quisiera como maestro, entre lo que ocurre en la clase y lo que ésta me sugiere en mi propia vivencia, entre la vivencia de quien comunica y la de quien escucha. La clase es un 
lugar para relacionar ideas, experiencias, lecturas, propuestas, acciones, un espacio para relacionarme como quien soy, sin ser juzgado. ${ }^{36}$

Entiendo que la confianza sólo se puede cuidar dando confianza, confiando. Pero, tenemos espacios instituidos, como es el del diario, que ayudan a probarlo, a probar si realmente podemos confiar unos en otros. Un momento de atenta escucha y de conversación sin juicio, en el que buscamos seguir el hilo de lo que nos despierta el diario, no entrando en polémica sobre lo que piensa su autor, cuidando la línea tenue que hay entre poder tener otro punto de vista sobre las cosas y no invadir lo que el otro muestra de sí, y que lo mueve al respeto. El diario, por sí mismo, por ser una obra muy personal, nos despierta la sabiduría implícita de lo que es cultivar la confianza. Yo trato de estar atento a que ese espíritu esté presente en todas nuestras relaciones, incluso en mis acciones relacionadas a la evaluación (procuro postergar tanto cuanto puedo las calificaciones y buscar formas compartidas con los propios estudiantes para solucionar ese problema administrativo). La disposición en el aula, las formas como nos hablamos, los detalles de la relación cuidada son fundamentales. Pero, también es fundamental que los tiempos de clase sean momentos para plantearse el sentido de lo que hacemos, para buscar las cualidades de las cosas, conversar sobre nuestras dificultades y desacuerdos, para que la gente pueda ser reconocida, incluso en su silencio o timidez, y respetada en sus posturas. Que sean momentos para que cada uno pueda manifestar sus discrepancias con las reflexiones, experiencias y propuestas pedagógicas que intento promover en la asignatura, que se pueda hablar desde su verdad, no sólo desde su capacidad de argumentar, sino desde sus inquietudes, temores, o desconciertos. Que también sean momentos para sentirse siempre acogidos: en sí mismos, pero también en sus opiniones y posiciones; y que eso no signifique complacencia, o todo es permitido, o "cada cual piensa lo que quiere". Es como un trabajo de filigrana, en el cual es necesario moverse sutilmente por los hilos de muchos aspectos pedagógicos y personales, jy eso es aún más difícil con 80 alumnos en la clase!

\section{CONTENIDO Y FORMA}

Como creo que ya se ha podido observar, tengo como principal preocupación ya no una coherencia entre aquello de lo que hablamos y lo que hacemos, sino la convicción de que lo fundamental en nuestro aprendizaje, del ser docente y de acompañar y apoyar los procesos de enseñanza y aprendizaje, no se vive tanto por lo que se dice, sino por lo que se hace, que en gran medida ese es un proceso poco consciente, mejor aún, que pasa primero por los poros de la piel, por el cuerpo. Mis preocupaciones pedagógicas 
fundamentales (para ellos que son mis estudiantes y también para cualquier niño o niña que tendrán en sus clases) se dirigen a la posibilidad de que sean respetados, escuchados, entendidos y a que encontremos la forma en la cual mirar a la infancia que menos invade su ser, la que más los mueve a abrir posibilidades de ser. Lo que hay en juego es cómo miramos a los niños, cómo los escuchamos, cómo nos relacionamos y cómo conversamos con ellos. Es allí de donde tiene que nacer todo lo demás. Eso no se puede enseñar, tan sólo se puede aprender. Muchos de mis estudiantes llegan a mí con la aspiración de aprender un saber técnico, cierto y seguro que les solucionará los problemas de la relación y de la enseñanza. Pero, lo único que cabe es atreverse a vivir y, por lo tanto, cultivar una manera de vivir; es atreverse a la relación con los niños y niñas; es conseguir ver y escuchar; es preguntarse por lo que tienen como mundo propio y cultural para compartir con sus alumnos, para que ellos también experimenten el vivir y amplíen sus posibilidades de experiencias de vivencia; $y$ es entender que esa la cultura es lo que tenemos para poner a su alcance, porque la cultura para eso es. ${ }^{37}$

Pienso que lo fundamental de la formación del profesorado es que puedan apreciar lo que parece predisponerse para eso, para esa escucha, para esas preguntas, para el vivir esa relación a partir de quienes son, de lo que tienen como propio, de lo que están dispuestos a compartir. Lo paradójico de la formación y de la Didáctica es que su propósito es, en el fondo, algo por aprender, pero que no se puede enseñar. Es que enseñar -en expresión de Elisabeth Ellsworth ${ }^{38}$ es como dar algo que no se tiene. Pero, como bien dice Vivian Paley ${ }^{39}$, enseñar es algo que no se hace en lo abstracto, sino en lo concreto. ${ }^{40}$ No se trata, pues, de cómo sustituimos algo que no sabemos dar por un discurso abstracto acerca de "las cualidades del profesor". La posibilidad de la educación se sostiene en las relaciones que abrimos, que cuidamos, que propiciamos, que ayudamos a que puedan darse. La Didáctica no puede ocuparse de lo que ocurrirá en la relación educativa; no puede decir lo que tiene que ocurrir en esa relación, ni puede programarla, no la puede tecnificar. El saber pedagógico no existe para interponerse en la relación educativa, que es siempre una relación en primera persona, pero puede tratar de ello en un lenguaje que ayude a pensar. Como el saber pedagógico tiene que obrar sobre la vivencia, sobre el experimentar relaciones $y$ atender a lo que tienen, a lo que cuidan, a lo que hay en ellas, a lo que permiten, a lo que abren o a lo que cierran, consecuentemente, el aprendizaje de la deliberación pasa por el experimentar en sí la relación entre ser, hacer y saber.

La formación del profesorado siempre debe siempre plantear en primer lugar esa experiencia, para que cada uno pueda encontrar un lenguaje 
que le ayude a pensarse, a mirarse en lo que colabora o entorpece, para que cada uno y cada una, pueda cultivar sus disposición de apertura hacia el otro.

\section{CRISIS PRODUCTIVAS: ENSEÑAR LO QUE APRENDO}

Aprender a ser profesor tiene que ver más con lo que se hace que con lo que se dice $y$, en todo caso, lo que se dice tiene que venir al lado de lo que se hace, abriendo espacio a ese hacer y a la posibilidad de un nuevo hacer. Eso, para mí, no es "una teoría", por lo contrario, es algo que he comprendido en la medida que he atendido a lo que me ocurre, buscando expresión para lo que vivo y nuevas salidas a lo que me ocurría, a lo que me impedía ver que la dificultad es por donde tengo que transitar para entender algo de lo que constituye el oficio docente y, en particular, la formación del profesorado. Por supuesto, inspirándome en otras experiencias, en la sabiduría que proviene de quienes han conducido su reflexión educativa "sin dejar al tiempo solo", mi saber pedagógico es, en gran medida, el que vivo, incluso con sus contradicciones y dificultades. Lo que sé y lo que trato de enseñar es lo que aprendo. Con eso, quiero decir que, además de que haya que practicar lo que se predica, pienso que mi gran aprendizaje como profesor, aquel que se me ha abierto con claridad en estos últimos años, ha sido más bien un movimiento contrario: que tengo que enseñar lo que voy aprendiendo, que es mi aprendizaje como docente al que tengo que conseguir hacerles llegar. ${ }^{41}$

En cursos anteriores, ya en el último mes de clase, en el momento de la lectura del diario, una alumna presentó una crítica demoledora a la asignatura. Sus argumentos podían resumirse en una idea principal: estaba acabando el curso y todavía no había entendido su función. “Creo -decía textualmente- que a un mes de terminar las clases, más de uno no ha podido llegar a entender, a deducir, aún, de que trata esta asignatura, es decir, ¿qué trabajamos? y ¿cuál es el objetivo? En ningún momento, he tenido claro el'hilo conductor' de esta asignatura". En primer lugar, mi sorpresa fue mayúscula porque yo no tenía consciencia de que eso estuviera pasando. Claro que sabía que había quienes seguían mejor o peor el ritmo del curso, pero yo lo atribuía, sobre todo, a la dificultad que algunos tenía para cumplir toda la carga de trabajo del curso, en un momento en que se instaló, en mi universidad, toda la modalidad hiperactiva de lo que llaman "créditos europeos", provocando que muchos estudiantes fueran desbordados. Sin embargo, lo que estaba diciendo aquella estudiante era algo muy diferente.

Por supuesto, en aquel día, hasta el final de la sesión, la clase se concentró en ese problema, demandándome un sobreesfuerzo entre sentirme afectado de una forma dolorosa por ese comentario y querer sobreponerme 
a él, intentando ver lo que me decían y que tenía que escuchar, a la vez que tenía que aclarar aspectos que pienso que no siempre tenían que ver con mi responsabilidad, sino con la suya (e inevitablemente, me sentía atrapado entre mantenerme ecuánime y ponerme a la defensiva, pero procuraba que no se me notara). A lo largo de la sesión, intentamos aclarar lo que era pertinente a la comprensión sobre el sentido de la asignatura y el modo de trabajar que seguíamos, deslindando ese particular de otras cuestiones organizativas referentes a las tareas que tenían que realizar y que se les habían amontonado al final, a sus inseguridades sobre las calificaciones, a las dificultades para aceptar algunos planteamientos pedagógicos que yo les acercaba a partir de experiencias que leían, a las visitas que algunas maestras nos habían hecho. Por supuesto, se presentaba una situación de difícil solución entre quienes estaban quejumbrosos y quienes no lo estaban pero no querían manifestarse para no entrar en conflicto con algunos de sus compañeros.

Pero, por lo que se refiere al problema principal, manifestaban algo que yo no podía dejar de escuchar: había una parte del grupo que no sabían a dónde íbamos, cuando ya estábamos acabando el curso. Para algunos, las clases eran muy "filosóficas", Ilena de grandes frases y grandes mensajes, pero seguían sin saber qué hacer. Por supuesto, yo podía decir que justo eran aquellos estudiantes que asistían irregularmente a las clases, pero eso no solucionaba nada, porque entre inasistencia e incomprensión, era difícil averiguar cuál era la causa y cuál el efecto.

Más allá de quién tenía razón, de cuál era la verdad de todo eso, se produjo algo que fue para mí el efecto fundamental de todo: me hundí. Justo en aquel curso, había comenzado a implementar la forma de trabajo en las clases que he expuesto anteriormente en sus líneas generales. Estaba convencido de que les conducía a la posibilidad de emprender tareas con cierta autonomía, lo que les permitía mediar por sí mismos entre lo que yo les ofrecía, y la forma en la que orientaban sus procesos y convicciones, construyendo sus ideas pedagógicas, en diálogo con experiencias. Estaba cuidando especialmente de las clases como un espacio en donde podíamos debatir el sentido de las tareas y lo que significaban, colocando las bases para su oficio docente. En definitiva, estaba muy satisfecho conmigo mismo. Sin embargo, me encontré con ese chaparrón. Los sentimientos que me afloraron fueron muchos y variados, pero todos negativos: me sentía dolido, incapaz, mal profesor, iluso, auto engañado, pero también engañado por mis propios alumnos, que habían mantenido la ficción hasta que alguien se atrevió a destaparla. A partir de ese momento, sentí que tenía la clase en mi contra; cualquier comentario que veía hacer por debajo, pensaba que era 
contra mí; me sentía incapaz de reconducir la clase y lo único que deseaba era que acabara un curso que ya no tenía remedio. Como consecuencia de eso, me auto flagelaba, lo que es, en el fondo, un tipo de auto indulgencia muy especial, en la que al tiempo que uno se castiga se auto conmisera.

Creo que fue en la siguiente clase, cuando a uno de los alumnos, con el que siempre había sentido que había una corriente de mutua simpatía, lo vi especialmente desconcentrado y pensé que, efectivamente, estaba perdiendo el afecto de todos. Decidí hablar con él, para ver qué pasaba; mi sorpresa fue que me desdijo de lo que yo estaba pensando; se disculpó por su manera de estar en clase y me dijo: "mira, yo creo que por encima de todo lo que cuenta es si estás con profesores que sean buenas personas, y tú, tengo claro que eres una buena persona". Su comentario, aunque ambivalente en muchos aspectos, me permitió empezar a pensar y remontarme; me encaminó a pensar con claridad. Por supuesto, conté también con el apoyo de colegas con los que compartí lo que me estaba pasando y que me ayudaron a poner las cosas en su sitio, lo que, en realidad, significaba ponerme a mí en mi sitio, encontrar la forma de relacionarme con lo que había pasado y con lo que me había pasado.

Al pensar en el comentario de aquel alumno, recordé dos anécdotas. La primera fue en una escuela de primaria. Participaba en un asesoramiento a aquella escuela y una maestra nos contaba cómo había intentado explicarles a sus alumnos de primer año algo relativo a la sustracción: intentaba que entendieran la notación formal a partir de ejemplos de situaciones cotidianas de resta; pero los niños, aunque entendían muy bien la resta, no entendían la necesidad de la notación formal y todo el proceso de clase entró en un callejón sin salida y la maestra se colapsó. Tras explicarnos todo eso, nos dijo: "menos mal que cuando volví con ellos en la tarde pude ver que todavía me querían." Lo que hizo que recordara esa situación fue la sensación de estar viviendo algo parecido. En aquel momento me di cuenta de que siempre había interpretado esa anécdota como la importancia de que el vínculo pueda mantenerse, de que mientras se mantenga el vínculo, siempre habrá una posibilidad de restaurar lo que se ha estropeado o perdido y que eso a mí también me daba una esperanza. Sin embargo, ahora podía ver también que esa anécdota se podía interpretar de otra manera: el deseo de sentirse querido puede ser movido por el ego, que es pensar en uno mismo y ver las situaciones desde su propio punto de vista, desde cómo se ha llevado con ellas, y no desde el punto de vista de los niños, por ejemplo, y lo que para ellos significa eso que está pasando, o lo que ocurre en la relación y ver si esa situación fluye o no. En mi caso, significaba que mi dolor era un dolor por mí mismo. 
Pude pensar eso porque recordé otra situación. Años atrás, un estudiante de doctorado asistió durante un tiempo a mis clases, y tras unos días de observación me dijo que yo estaba enamorado de mis alumnos de magisterio. La verdad es que el comentario me molestó; pensé que no había sido capaz de interpretar lo que yo estaba tratando de hacer con mis alumnos; llamaba enamoramiento a mi entrega, a mi deseo de movilizarlos, de provocarles, de eso que he llamado "enardecimiento". Sin embargo, ahora podía entender que tenía razón. En mi forma de actuar había un fuerte impulso del ego: el deseo de ser querido, apreciado como el profesor que"les abría los ojos"y les mostraba "el camino". La crítica que yo recibí en el diario de aquella alumna -ahora lo podía ver- era en el fondo una crítica a mi ego; estaba tan contento de mí mismo que no podía ver lo que estaba pasando, al menos con algunos de mis estudiantes; esperaba tanto de ellos, gracias a mis clases, que en realidad no los miraba. Esperaba tanto que no podía aceptar la realidad y esta se volvía contra mí. Lo quería todo, lo esperaba todo. Mi dolor era también el dolor de no ser el profesor perfecto que quiere y consigue cosas maravillosas de sus alumnos.

El aprendizaje de esa historia ha sido precisamente este: dejar el ego y escuchar la experiencia de ellos. Sé que pretendo cosas difíciles y sutiles. Sé que les estoy pidiendo algo complicado. Precisamente por eso, tengo que estar más a la escucha, para ver lo que realmente significa para ellos lo que les propongo. Si estoy más a la escucha, estoy menos preocupado sobre si son o no lo que espero que sean. Me observo menos a mí en comparación con lo que espero de ellos y estoy más pendiente de ver lo que sucede y de pensar de forma adecuada a partir de lo que sucede y no de mí. Observarlos a ellos es lo que me permite estar más suelto para ver lo adecuado. Observarme a mí, ya sea para sentirme dolido, defraudado o satisfecho, me impide estar atento a la necesidad de la relación. Ahora sé, por ejemplo, que, desde un principio, tengo que estar más pendiente de ellos y de sus dudas, tengo que seguirlos más de cerca y estar atento a los síntomas; tengo que ser más claro en lo que les propongo y no sutil en esa transmisión de las maravillas pedagógicas que deseo y espero. Entender que el aprendizaje del curso tiene que ser una mediación entre la realidad que han vivido y que sospechan o quieren y las propuestas que les hago; que la tarea consiste en ir encontrando cada uno su lugar en la relación que quiere tener con el contenido del curso, siguiendo su propio proceso, decidiendo sobre sí y sobre su relación con la práctica docente. Eso es lo que tengo que hacerles ver. Tengo que entender que eso genera miedo e inseguridad y que algunos prefieren la comodidad o no están en condiciones de asumir el riesgo de vivir desde sí, asumiendo 
la libertad, explorando modos de ser y vivir. Tengo que considerar que no soy el profesor perfecto, que les puedo enseñar algunas cosas, pero otras no. Necesito también entender un problema que siempre señalan todas las críticas a una Didáctica que no se propone a sí misma como la solucionadora técnica de la enseñanza: que si la formación del profesorado separa el tiempo de formación del tiempo de la experiencia cotidiana con niños y niñas, se crea un vacío que no puede remitir a "ya harás las prácticas y practicarás todo lo aprendido".

Lo fundamental que he podido obtener de esa historia vivida es, sobre todo, no estar pendiente de mí, sino de lo que sucede. He podido darme cuenta de que muchos de los problemas que vivimos los docentes están afectados por esto: estar más pendientes de sí mismos que de mirar lo que hay. Eso puede ser causado por miedo (porque vemos el miedo que nos produce la situación, en vez de la situación), o por lo que llamo el "buenismo" (nuestro deseo de ayudar y hacer algo para sentirnos bien y tranquilizar nuestra conciencia), y que no deja de ser el hecho de pensar más en uno mismo que en el otro, en lo que la situación o el otro necesita. Ha sido esa experiencia y los análisis y reflexiones, a los que me vi abocado, lo que me ha hecho transformar, de una manera sutil pero profunda, mi relación con mi enseñanza. Ha sido eso lo que me ha hecho poder relacionarme de otra forma con la dificultad, porque entiendo ahora que la enseñanza es una experiencia que se inicia con la intención de que algo ocurra, pero que se vive sin esperar nada. Mi mirada no está en ellos, sino en lo que hacemos, en lo que nace como conversación. Procuro mediar entre lo que va surgiendo y les va pasando para que encuentren su camino. Mi experiencia ha sido que al estar menos preocupado por mí y por la reacción que espero de ellos, estoy más abierto a acoger lo que sucede, a dejarme llevar y a dejarme inspirar por lo que la situación me va sugiriendo. Estoy convencido de que lo sutil tiene su efecto mágico en el sentido de que, como no espero nada, todo puede suceder. Como no hay una carga de expectativas sobre ellos, que pese como una losa, como algo que yo esperaba sin que ellos supieran qué, resulta que ahora tienen más libertad para explorar y seguir su propio camino, sus propias confusiones, sus hallazgos, su empezar la carrera de ser maestros. Yo he ganado en libertad y en ligereza y ellos también.

Eso es, en el fondo, lo más importante de lo que quería contarles con esa historia, haber pensado en lo que me pasó y haber extraído de ello lecciones que me han dado también un nuevo saber que ahora puedo poner en juego en las clases. Ese saber me permite dialogar con mis estudiantes sobre lo que les pasa y cómo viven su relación con las situaciones educativas 
que tienen o que imaginan en su futuro profesional. Ese saber me da más capacidad para orientarles a cómo mirar las situaciones educativas que analizamos y para darles recursos para que piensen sobre sí mismos como maestros, tratando de entender no sólo cómo enseñar, sino cómo mirar su relación con el enseñar; no sólo cómo mirar a la infancia, sino cómo dedicar atención a su relación con la infancia; no sólo cómo transformar la realidad, sino, como han señalado las feministas italianas, cómo transformar su relación con la realidad ${ }^{42}$.

Todo esto, la experiencia de esos años y los cambios que he visto en mí me han dirigido a pensar cada vez con más claridad que la Didáctica, más que una disciplina que enseño, es un espacio formativo que despliego y comparto con mis estudiantes. Entiendo, así, que la Didáctica es como un saber que se asocia bien con la experiencia educativa, un saber sobre lo que sostiene y lo que orienta la acción; un saber que tiene que ser vivido en primera persona; por eso, es necesariamente un saber inconcluso que sólo existe si alguien lo recibe y lo completa de tal forma que le predisponga a vivir una experiencia; un saber que no lo dice todo, que no acaba la frase, que tiene que ser reactualizado a cada vez y que siempre está a la espera de ser acabado de significar. Un saber como el saber de la vida.

EXPERIENCE, WRITING AND DELIBERATION: EXPLORING WAYS OF FREEDOM INTHE DIDACTIC TRAINING OF TEACHERS

ABSTRACT: This paper presents a reflection that involves the author's experience as a teacher trainer, reinforcing that this function is the hardest job in the world, but also one with which you feel most identified and worried. Assumes the need for transformation in the way we have designed and worked in teacher training, giving opportunity to new ways of looking at the formation and the formation of this subject. When discussing the possibility of transforming this relationship in training contexts, states that this also involves the movement of world transformation, the school, which involves paths to freedom.

Keywords: School. Teaching. Teacher training.

EXPERIÊNCIA, ESCRITURA E DELIBERAÇÃO: EXPLORANDO CAMINHOS DE LIBERDADE NA FORMAÇÃO DIDÁTICA DO PROFESSORADO

REsUmo: O texto traz uma reflexão que envolve a experiência do autor como formador de professores, reforçando que esta função é o trabalho mais difícil do mundo, mas também aquele com o qual se sente mais identificado e preocupado. Assume a necessidade da transformação no modo como temos concebido e atuado na formação de professores, dando oportunidade a novas maneiras de olhar a formação e os sujeitos 
dessa formação. Ao discutir a possibilidade de transformar essa relação nos contextos formativos, afirma que essa passa também pelo movimento de transformação do mundo, da escola, que envolve caminhos para a liberdade.

Palavras-Chave: Escola. Didática. Formação de professores.

\section{NOTAS}

1. Agradezco la lectura atenta de este texto por parte de Nuria Pérez de Lara, Montse Ventura y Ángel Pérez Gómez, así como los comentarios y sugerencias que me han hecho para su mejoría.

2. He desarrollado con más detenimiento esta idea en otros trabajos (CONTRERAS, 2005; en prensa).

3. En sus últimas obras Max Van Manen ha insistido en esta idea fundamental de lo pedagógico: “La pedagogía 'consiste' en este constante cuestionamiento; es este dudar siempre. Nos preguntamos: ¿he hecho lo correcto?" (VAN MANEN, 2003, p. 162). Pueden verse también Van Manen, 1998, 2004.

4. Sobre la noción de experiencia, sus múltiples significados y su sentido formativo pueden verse en los escritos de Jorge Larrosa (2003; 2006).

5. Zambrano (1989a, p. 107).

6. Mortari (2002, p. 155).

7. Esta forma de entender el pensar queda muy claramente expresada en esta cita de María Zambrano: "Pensar no es sólo captar los objetos, las realidades que están frente 'al sujeto' y a distancia. El pensar tiene un movimiento interno que se verifica dentro del propio sujeto, por así decir. Si el pensar no barre la casa por dentro, sería simple clarificación lógica en que se repite lo ya pensado desde afuera." (1989b, p. 82).

8. En otro lugar (CONTRERAS, 2003, pp. 23-27), he relatado todo este proceso y cómo ha influenciado en mis replanteamientos, tanto sobre la concepción de la Didáctica como de su enseñanza, una serie de experiencias vividas que me han permitido estar más centrado en la relación de búsqueda entre mi pensar y mi hacer.

9. En este mismo texto, dedicado al análisis de las formas en que había evolucionado mi visión de la enseñanza de la Didáctica, señalaba precisamente los problemas que percibía entonces en la forma en que se concebía este conocimiento, ver Contreras (2003, pp. 22-23).

10. Zambrano (2000, pp. 73-74).

11. Ibídem, p. 83.

12. Ibíd. p. 85.

13. lbíd. pp. 88-90.

14. Zambrano (1989a, p. 15). 
15. Pueden verse más detalles de ese momento en mi forma de concebir la enseñanza de la Didáctica en el texto anteriormente citado (CONTRERAS, 2003).

16. Zambrano (2000, p. 86).

\section{Ibídem.}

18. Conviene aclarar que, para mí, esta posición no significa abandonar el legado del saber pedagógico y de los conocimientos que se han podido constituir a partir de la investigación y de la teorización o, en general, los aportes de las ciencias humanas y sociales; lo que Mireille Cifali (2005, p. 179) ha llamado de "los saberes constituidos". Como ha señalado esa autora, estos saberes permiten una descentralización respecto al saber que cada cual ha construido a partir de su relación consigo mismo y con los otros, con la sociedad y sus instituciones, así como han permitido un cuestionamiento sobre el proceso mismo de conocer.

19. Anna Ma Piussi (2006, p. 20).

20. Muraro (2004).

21. Sobre la importancia de la narrativa en la enseñanza puede consultarse McEwan y Egan (1998). Para profundizar en lo que la narrativa denota como modo de relacionarse con la experiencia e indagar en ella, o sea, entendiendo la narrativa como un modo de conocer, resulta especialmente sugerente el trabajo de Carola Conle (1999; 2000). Un estudio reciente de la relación entre experiencia y escritura narrativa es el de la tesis doctoral de Marta Caramés (2008).

22. Encuentro muy valiosa la aportación de Anna R. Ershler (2003), en relación a la narrativa, los relatos sobre la propia experiencia de docentes en formación y la cualidad que la autora resalta en este tipo de relatos: "incluirse en el texto"; es decir, verse en la acción, ser quien vive, siente y piensa sobre lo vivido, siendo uno mismo parte de lo pensado.

23. Mireille Cifali (2005, p. 189) ha planteado que "el relato sería el espacio teórico de las prácticas [...] Esta escritura, cercana a la literatura, [...] podría verse como una de las formas de inteligibilidad de las situaciones de lo vivo".

24. También la lectura de narrativa, y no sólo la escritura, es importante para eso, según ha mostrado en su tesis doctoral Mar Esteve (2007).

25. Mireille Cifali (2005, p. 192) ha hablado sobre esa necesidad de expresión de lo que no se suele hablar (ya sean los afectos, o las dificultades y problemas), de encontrar un lenguaje para recuperar lo que la racionalidad científica ha olvidado y de expresar aquellas dimensiones íntimas, personales, como los sentimientos: "Confesar los sentimientos equivale a hacer un lugar al otro y aceptar que éste nos puede afectar; escribirlos es atreverse a decir'yo'y a ocupar el lugar que nos corresponde en la acción".

26. Hace ya muchos años que propongo a mis estudiantes la tarea de escribir la historia de su propia infancia, pero, con el tiempo, la he conducido a convertirse en un registro que no se limita exclusivamente al análisis crítico de su vida escolar, lo que hacía al 
principio, sino que intente explorar más cosas (si bien no siempre con mucho éxito, pero también sin obsesiones por mi parte, porque soy consciente de la dificultad de lo que les pido). Sobre el uso de la biografía escolar y su valor para el estudio crítico de la enseñanza pueden verse Ma Cristina Davini (1995) y Remei Arnaus (1999). Sobre la importancia de la propia historia de niñez en la tarea docente, resulta especialmente sugerente la obra de Georges Jean (1982). Sobre las formas de trabajar en la indagación de la propia historia personal para la formación del profesorado, puede consultarse Florence Krall (1988).

27. Aprovechando que la mayoría de los estudiantes que tengo tienen experiencia de actividades y relaciones diversas con niños y niñas (monitores de tiempo libre etc), les pido a quienes quieran que escriban algo de su experiencia (de lo que les va bien o mal, de sus logros y dificultades), para compartirlo con la clase. Es enfoque que les pido que desarrollen es el de fijarse en lo que a ellos los motiva como educadores en lo que hacen y buscan, y la manera como lo aclaran no como una idea previa, sino en la experiencia concreta de su actividad con los niños. De esa manera, lo que busco es atender a la necesidad de explorarse para pensar tanto en aquello que tienen de propio, con lo que pueden contar de sí, como en lo que tienen que contrastar para repensarse, a fin de buscar el sentido de lo educativo en el diálogo consigo mismo, y con otros, como forma de irse haciendo maestros y maestras.

28. Un relato de esa forma de enfocar la tarea, de las repercusiones que tuvo sobre mis clases y las reflexiones que me provocaron lo he publicado en Contreras (2006).

29. Por otra parte, el diario es probablemente el lugar en el que más y mejor los alumnos experimentan (cuando escriben y cuando oyen el de sus compañeros) todas aquellas cualidades de la relación entre el vivir y el pensar lo vivido, buscando el propio sentido y elaborando su propia comprensión. Suele estar presente en sus textos una reflexividad, en la medida en que buscan, precisamente, mostrar sus modos de ver, pensar, sentir o hacer en relación a lo que hablan, siempre poniéndose en juego, buscando algo que decir que sea propio y que mueva a quienes les escuchan a una conexión con lo que dicen. Son textos que al ser muy personales y con clara intención de que sean escuchados, buscan un lenguaje con el que mejor creen expresar lo que quieren decir, y tantean una cuestión siempre delicada que es la de exponerse, la de decir algo propio al resto del grupo.

30. He tomado esta expresión de Begoña González, educadora y directora de "El Roure" una escuela fuera de lo convencional. Puede verse una aproximación a esa escuela en (GONZÁLEZ, 2004). He desarrollado más esta idea del aprendizaje personal en (CONTRERAS, en prensa).

31. Entiendo mi tarea no como separada en dos tiempos: el de hacerles llegar esas ideas y reflexiones; y el de que hagan algo con ello. Más bien es casi al revés, es la necesidad de hacer algo con esos interrogantes nacientes lo que nos conducen a relacionarnos con ideas, experiencias, relatos etc, buscando cada uno cómo profundizar en sus preguntas y construir su camino personal en las respuestas. Así, aunque 
yo les proponga un plan de trabajo para el curso, con múltiples tareas y lecturas, mi aspiración es que puedan vivirlas desde los interrogantes e intereses que ya estén vivos en ellos y en nuestras clases.

32. Son ejemplos de tareas que les propongo (además de las ya mencionadas sobre historia de su niñez o sus experiencias como educadores), la de elaborar los rasgos de la cultura escolar; construir y analizar "Unidades Didácticas" con diferentes planteamientos y con diferentes propósitos en el trabajo que realizamos con ellas mientras se construyen; analizar libros de texto u otros materiales curriculares; seguir o reconstruir la historia de una persona con necesidades especiales; definir las líneas pedagógicas generales de su proyecto de escuela. A todas esas propuestas les acompaña siempre una serie de lecturas que deben realizarse, así como preguntas y reflexiones que deben abordarse y responderse al realizar las tareas. Procuro que cada tarea sea no sólo un "hacer lo que se pide", sino que contenga, en su propia presentación, elementos que dirigen los estudiantes hacia la reflexión, la deliberación y la asunción personal del enfoque que adquieren las mismas.

33. ¿Significa esto primar la Formación por encima de la Didáctica? En realidad, pienso que ésa es una falsa pregunta. Porque, ¿tiene algún sentido la Didáctica, que no sea el de la Formación? Desde luego, si la Didáctica aspira ser un saber pedagógico, no puede ser más que un saber al servicio de la formación pedagógica. Es probable que detrás de esa posible disputa haya una separación, para mí inaceptable, entre enseñanza y educación. Cualquier proceso de enseñanza es siempre un proceso con una pregunta educativa por detrás: ¿Qué relación establecemos con el saber, tanto quien lo enseña como quien lo aprende? ¿Quién soy yo aprendiendo? ¿Qué hace el saber y la experiencia de saber en mí? Cualquier proceso de enseñanza significa la oportunidad de una experiencia educativa, o su frustración. Por consiguiente, cualquier proceso de aprendizaje de la Didáctica nos plantea por partida doble esta cuestión. Porque, además de plantearse la necesidad de abordar como contenido de la Didáctica esa pregunta sobre el valor educativo de cualquier enseñanza o aprendizaje, la experiencia de la enseñanza y del aprendizaje de la Didáctica nos interroga sobre quienes somos nosotros aprendiendo o enseñando Didáctica. ¿Es el aprendizaje de la Didáctica la oportunidad de vivir una experiencia de formación? Evidentemente esa pregunta es válida siempre en cualquier caso para cualquier disciplina en el ámbito de la formación del profesorado: ¿Es el aprendizaje de cualquier materia una oportunidad de vivir una experiencia de formación? ¿Es una oportunidad de vivir una experiencia de formación, de transformación, en cuanto docentes?

34. Digo 'los roles' expresamente como algo diferente a asumir en la relación el ser maestro y el ser discípulo. Al decir rol, me refiero a la asignación del papel institucional, y por lo tanto a actuar no como quien se es, sino en representación de la institución.

35. Por otra parte, inspirado en la tradición del Portafolio docente (LYONS, 1999), les propongo a los estudiantes la realización de lo que llamo una "carpeta-memoria de aprendizaje". Su sentido, lo encuentro en que dispongan de una demanda reflexiva 
en la que puedan componer lo que les es importante para su proceso de formación, o que exploren formas de expresarse y describir ese proceso, y además que se pregunten en todo lo que hacemos qué significa para ellos ese hacerse maestros. De ese modo, abro un aspecto fundamental en la realización del curso: que piensen en su proceso de aprender, que lo compongan al hacer algo personal con lo que hacemos en clase; que se pregunten cómo aprenden y por lo tanto que piensen en qué es aprender de una manera concreta y personal; que puedan observar en sí la relación entre experiencia y saber. Una necesidad para ellos y para mí, dada la distorsión del saber como conocimiento "exento" (eso es, proposiciones formalizadas, que proceden de un afuera que lo transmite); lo cual a veces produce en ellos la sensación de que no aprenden, porque no disponen de un corpus transmitido y ordenado de "conocimientos". Hay efectivamente un peligro de que no aprendan si no hacen un proceso consciente de dar forma y orden a lo que se trabaja, intercambiando, leyendo, interrogándonos a lo largo del curso.

36. Procuro que en el tiempo de clase haya un ambiente poco ocupado por la transmisión (las lecturas permiten suplir mejor esa necesidad, sin tener que llenar el tiempo de clase) y más por la oportunidad de conocer y estudiar experiencias educativas (desde visitas de enseñantes hasta documentales y textos que relatan estas experiencias, o bien historias, y situaciones para analizar y plantearnos cómo pueden ser entendidas y cómo orientar el sentido de la acción pedagógica en esas circunstancias).

37. Cristina Mecenero (2003), una maestra italiana, ha expresado muy bien, qué relación hay entre escuchar a sus alumnas y alumnos y preguntarse, como docente, sobre lo que el mundo de la cultura tiene para ofrecerles, así como lo que nuestra sociedad y cultura puede aprender escuchando a los niños. He desarrollado más esas ideas en Contreras (2002; 2005; en prensa)

38. Ellsworth (2005, p. 27).

39. Paley (2006, p. 28).

40. Es importante para mí insistir en eso porque lo que estoy defendiendo no es un hablar a los estudiantes sobre el "sentido", sin vivencias concretas en lo planteen, ni tampoco ideas genéricas de cualidades pedagógicas que mis estudiantes tengan que buscar con sus futuros alumnos de forma abstracta. Por eso, una de las búsquedas fundamentales del curso es la de formas de enseñanza, modos de hacer, maneras de relacionarse, caminos para abordar los conflictos y las dificultades en las aulas etc. Al contrario de lo que se suele pensar, no pienso que sea algo contra "las recetas", sino sobre el peligro de no transmitir bien lo que en una receta hay de sentido, y de recibirla como una solución a los problemas, y no como un camino de búsqueda que cada cual recibe junto con una fórmula particular para ello; es ese modo de recepción (que requiere cuidado en la transmisión) el que hace posible la libertad para recrear cada uno la receta al recibirla, al haber captado, junto con la fórmula, su sentido. Ese es el sentido del libro del grupo de mujeres educadoras Sofías (2004), titulado precisamente Recetas de relación. 
41. "Por supuesto que lo que uno puede aprender de su propia experiencia son muchas cosas, y que cuando las cosas te salen bien, puedes apreciar lo que ha pasado, lo que se ha dado, para poder ir construyendo a partir de ahí lo que va bien para tus clases, y puedes así ir elaborando las ideas que dan razón de lo que sostiene lo que estás haciendo, o las reflexiones que te ayudan a perfilar mejor tus pensamientos, a entender mejor lo que estás haciendo para ir expresando la comprensión, el saber que vas destilando de esa experiencia. Pero es también explorando tus propios límites, tratando de ver hasta dónde llegas y por qué tienes dificultades para ver más allá, para entender mejor por qué te encallas y no sabes (o no te atreves a) ir más lejos, qué es lo que no acaba de ir; es en este terreno de lo inseguro, de lo que aún no, en donde tienes tu mejor oportunidad de aprendizaje. Pero si vives tus límites como una dificultad negativa, como frustración y fracaso, lo más probable es que no te los quieras poner delante (o que no sepas cómo hacerlo). Como también es cierto que no es fácil ponerte ante tus ojos, o incluso ser consciente de esas tus limitaciones si no hay algo que te las pone delante descarnadamente. Es mejor no dejar traslucir nada pues podría ser utilizado en contra nuestra. Estamos aprisionados en encrucijadas políticas que nos impiden hacer públicas nuestras dudas y nuestros fracasos." (Cifali, 2005, p. 192).

42. Sobre esa potente idea de transformar nuestra relación con la realidad puede verse, Piussi (1999, p. 52)

\section{REFERENCIAS}

ARNAUS, Remei (1999) “La formación del profesorado: un encuentro comprometido con la complejidad educativa". En ANGULO RASCO, J. F.; BARQUÍN RUIZ, J.; PÉREZ GÓMEZ, A. I. (eds.) Desarrollo profesional del docente: política, investigación y práctica. Madrid: Akal, pp. 599-635.

CARAMÉS, Marta (2008) Tocant l'experiència de la relació educativa amb dones immigrades. Una recerca narrativa. Tesis Doctoral Barcelona: Universitat de Barcelona.

CIFALI, Mireille (2005) “Enfoque clínico, formación y escritura”. En PAQUAY, Léopold; ALTET, Marguerite; CHARLIER, Évelyne; PERRENOUD, Philippe (coords.) La formación profesional del maestro. Estrategias y competencias. México: Fondo de Cultura Económica.

CONLE, Carola (1999) "Why Narrative? Which Narrative? Struggling with Time and Place in Life and Research". Curriculum Inquiry, Vol. 29, № 1, pp. 7-32.

CONLE, Carola (2000) "Thesis as Narrative or 'What Is the Inquiry in Narrative Inquiry" Curriculum Inquiry, Vol. 30, № 2, pp. 189-214.

CONTRERAS, José (2002) “Política del currículum y deliberación pedagógica”. En Westbury, lan (comp.) ¿Hacia dónde va el currículum? La contribución de la teoría deliberadora. Massanet de la Selva (Girona): Pomares, pp. 75-109.

CONTRERAS, José (2003) “La Didáctica y la autorización del profesorado”. En ARANTES TIBALLI, Elianda F. y MATIAS CHAVES, Sandramara (orgs.) Concepções e práticas em formação de professores. Rio de Janeiro: DP\&A, pp. 11-31. 
CONTRERAS, José (2005) “La autonomía del profesor. En primera persona: liberar el deseo de educar". En GAIRÍN, Joaquín (coord.) La descentralización educativa ¿una solución o un problema? Las Rozas (Madrid): Cisspraxis, pp. 327-373.

CONTRERAS, José (2006) “La autonomía docente: Implicaciones para la formación del profesorado". En ESCUDERO, Juan Manuel, y LUÍS, Alberto (eds.) La formación del profesorado y la mejora de la educación. Barcelona: Octaedro, pp. 245-268.

CONTRERAS, José (en prensa) "Subjetividades em relação: Aberturas pedagógicas para personalizar o ensino" En CAMARGO, Ana Ma Faccioli, MARIGUELA, Marcio, y SOUZA, Regina Ma (orgs.) Que escola é essa?-Anacronismos, resistências e subjetividades. Campinas (São Paulo): Átomo \& Alínea.

Cuadernos de Pedagogía (2004) Otra educación, otras escuelas. № 341 (Monográfico coordinado por José Contreras).

DAVINI, Ma Cristina (1995) La formación docente en cuestión: política y pedagogía. Buenos Aires: Paidós.

ELLSWORTH, Elisabeth (2005) Posiciones en la enseñanza. Diferencia, pedagogía y el poder de la direccionalidad. Madrid: Akal.

ERSHLER, Anna R. (2003) "la narrativa como texto experiencial: incluirse en el texto". En LIEBERMAN, Ann y MILLER, Lynne (eds.) La indagación como base de la formación del profesorado y la mejora de la educación. Barcelona: Octaedro, pp. 193-208.

ESTEVE, Ma Mar (2007) L'experiència de la lectura en la formació pedagògica dels mestres. Tesis doctoral. Barcelona: Universitat de Barcelona.

FOUCAULT, Michel (1990) Tecnologías del yo. Barcelona: Paidós.

GONZÁLEZ, Begoña (2004) “El Roure. Una escuela para cuidar el alma infantil". Cuadernos de Pedagogía, № 341, págs. 30-34.

JEAN, Georges (1982) El profesor. Su cultura personal y su acción pedagógica. Madrid: Narcea.

KRALL, Florence R. (1988) "From the Inside Out - Personal History as Educational Research" Educational Theory, Vol. 38, № 4, pp. 467-479.

LARROSA, Jorge (2003) Entre las lenguas. Lenguaje y educación después de Babel. Barcelona: Laertes,

LARROSA, Jorge (2006) “Algunas notas sobre la experiencia y sus lenguajes” Estudios Filosóficos, Vol. LV, № 160, pp. 467-480.

Librería de Mujeres de Milán (1996) El final del patriarcado (Ha ocurrido y no por casualidad). Barcelona: Libreria Pròleg.

LYONS, Nona (1999) EI Uso de portafolios: propuestas para un nuevo profesionalismo docente. Buenos Aires: Amorrortu.

MANENTI, Elisabetta (2002) "La Casa del Po". En Diótima El perfume de la maestra. Barcelona: Icaria, pp. 162-175. 
McEWAN, Hunter y Egan, Kieran (comps.) (1998) La narrativa en la enseñanza, el aprendizaje y la investigación. Buenos Aires: Amorrortu.

MECENERO, Cristina (2003) “Cerca del comienzo". DUODA. Revista d'Estudis Feministes, № 25, págs. 103-109.

MORTARI, Luigina (2002) "Tras las huellas de un saber". En Diótima El perfume de la maestra. Barcelona: Icaria, pp. 153-162.

MURARO, Luisa (1994) El orden simbólico de la madre. Madrid: horas y HORAS.

MURARO, Luisa (2004) “Enseñar la libertad” Duoda, № 26.

PALEY, Vivian G. (2006) El niño que quería ser un helicóptero. El empleo de la narración de historias en el aula. Buenos Aires: Amorrortu.

PIUSSI, Anna Ma (1999) “Más allá de la igualdad: apoyarse en el deseo, en el partir de sí y en la práctica de las relaciones en la educación". En LOMAS, Carlos (comp.) ¿lgualeso diferentes? Género, diferencia sexual, lenguaje y educación. Barcelona: Paidós, pp. 43-67.

PIUSSI, Anna Ma (2006) “El sentido libre de la diferencia sexual en la educación", En PIUSSI, Anna Ma y MAÑERU, Ana (2006) Educación, nombre común femenino. Barcelona: Octaedro, pp. 15-45.

PIUSSI, Anna Ma y MAÑERU, Ana (2006) Educación, nombre común femenino. Barcelona: Octaedro.

SOFÍAS (2004) Recetas de Relación. Educar teniendo en cuenta a la madre. (Edición al cuidado de Ma Milagros Montoya Ramos). Madrid: horas y HORAS.

VAN MANEN, Max (1998) El tacto en la enseñanza. El significado de la sensibilidad pedagógica. Barcelona: Paidós.

VAN MANEN, Max (2003) Investigación educativa y experiencia vivida. Barcelona: Idea Books.

VAN MANEN, Max (2004) El tono en la enseñanza. El lenguaje de la pedagogía. Barcelona: Paidós.

ZAMBRANO, María (1989a) Notas de un método. Madrid: Mondadori

ZAMBRANO, María (1989b) Delirio y destino. Madrid: Mondadori

ZAMBRANO, María (2000) Hacia un saber sobre el alma. Madrid: Alianza.

JOSÉ CONTRERAS DOMINGO é doutor em Ciências da Educação da Universidade de Málaga. Professor de Ensino de Formação de Professores (1983-1992) da Universidade de Málaga, e atualmente da Universidade de Barcelona. É coordenador do Departamento de Educação da Universidade de Barcelona, área da Didática. Investiga a educação primária, professor e escolas alternativas e experiências de escolas inovadoras.

E-mail: jcontreras@ub.edu 